\author{
Abstracta Iranica \\ Abstracta Iranica Revue bibliographique pour le domaine irano-aryen \\ Volume 37-38-39 | 2018 \\ Comptes rendus des publications de 2014-2016
}

\title{
Karim Alizadeh, « Borderland Projects of Sasanian Empire: Intersection of Domestic and Foreign Policies »
}

Rika Gyselen

\author{
(2) OpenEdition \\ Journals \\ Édition électronique \\ URL : http://journals.openedition.org/abstractairanica/42623 \\ DOI : $10.4000 /$ abstractairanica. 42623 \\ ISBN : 1961-960X \\ ISSN : 1961-960X \\ Éditeur : \\ CNRS (UMR 7528 Mondes iraniens et indiens), Éditions de l'IFRI
}

\section{Référence électronique}

Rika Gyselen, « Karim Alizadeh, « Borderland Projects of Sasanian Empire: Intersection of Domestic and Foreign Policies » », Abstracta Iranica [En ligne], Volume 37-38-39 | 2018, document 4, mis en ligne le 10 mars 2018, consulté le 27 septembre 2020. URL : http://journals.openedition.org/

abstractairanica/42623 ; DOI : https://doi.org/10.4000/abstractairanica.42623

Ce document a été généré automatiquement le 27 septembre 2020.

Tous droits réservés 


\title{
Karim Alizadeh, « Borderland Projects of Sasanian Empire: Intersection of Domestic and Foreign Policies »
}

\author{
Rika Gyselen
}

\section{RÉFÉRENCE}

Karim Alizadeh, « Borderland Projects of Sasanian Empire: Intersection of Domestic and Foreign Policies ", in Richard Payne, Mehrnoush Soroush (ed.), The Archaeology of

Sasanian Politics. (Journal of Ancient History, special issue, 2.2), Berlin, De Gruyter, 2014, p. 93-115.

1 Les projets de l'état sassanide dans les régions périphériques avaient un but à la fois militaire - la défense contre les nomades par la construction de murs, de citadelles et de tours de défense - et économique - développer la région grâce à un système d'irrigation qui permet une agriculture intensive. Celle-ci devait permettre de produire la matière première pour des manufactures locales et un surplus alimentaire qui pourra être négocié avec d'autres régions. Des exemples très précis de cette démarche du pouvoir sassanide ont pu être mis en évidence grâce à des prospections et des fouilles archéologiques dans les régions à l'ouest et à l'est de la mer Caspienne, respectivement dans la région de Darband et dans le Mūgān à l'ouest, et le Gurgān à l'est. Contrairement à la tradition historiographique post-sassanide qui attribue presque systématiquement toutes les grandes initiatives à Husraw Ier, l'examen des vestiges archéologiques montre que les systèmes de défense et d'irrigation appartiennent au $\mathrm{Ve}$ siècle. Il faut en conclure que malgré les problèmes qu'ont rencontrés Yazdgerd II (438-457) et Pērōz (457-484) pendant leur règne, ils ont investi de façon déterminante dans la défense des frontières contre les populations qui nomadisaient au nord de 
l'empire et ont favorisé le peuplement de ces zones tampons en développant l'irrigation.

2 On peut ajouter à cet exposé que les sources sigillographiques également mettent bien en avant l'implication de Yazdgerd II et de Pērōz dans ces régions puisqu'on trouve des noms de provinces comme Šahr-pādār-Pērōz au sud du Caucase et Šahr-rām-Pērōz derrière le mur du Gurgān. En revanche, des provinces comme Ērān-xwarrah-Yazdgerd ou Šahr-winnārd-Yazdgerd-abzūd-Husraw n'ont pas encore pu être localisées.

\section{AUTEURS}

\section{RIKA GYSELEN}

CNRS, Mondes iranien et indien 